\title{
Why Some Make It and Others Do Not: Identifying Psychological Factors That Predict Career Success in Professional Adult Soccer
}

\author{
Nico W. Van Yperen \\ University of Groningen
}

\begin{abstract}
This prospective study was designed to identify psychological factors that predict career success in professional adult soccer. Post hoc, two groups were distinguished: (1) Male soccer players who successfully progressed into professional adult soccer ( $n$ $=18)$ and (2) Male soccer players who did not reach this level $(n=47)$. Differences between the two groups were examined on the basis of data gathered in the initial phase of their careers, 15 years earlier. The psychological factors that predicted career success while statistically controlling for initial performance level and demographic variables were goal commitment, engagement in problem-focused coping behaviors, and social support seeking. On the basis of their scores on the significant predictor and control variables, $84.6 \%$ of the adolescent youth players were classified correctly as successful or unsuccessful.
\end{abstract}

In the sports sciences, prospective studies on career success, indicating the ultimate performance outcome, are completely lacking. Psychological factors (in addition to factors such as motor skills and biometric qualities) are recognized as critical for the acquisition of sport expertise (e.g., Abbott \& Collins, 2002; Baker \& Horton, 2004; Bloom, 1985; Côté, Baker, \& Abernethy, 2003; Durand-Bush \& Salmela, 2002; Vaeyens, Lenoir, Williams, \& Philippaerts, 2008; Van Yperen, 1992), but the importance of these factors has not been demonstrated in studies using a prospective design. Hence, the current study was designed to identify psychological factors that predict career success in soccer, the largest sport worldwide (Szymanski \& Zimbalist, 2005). Predictor variables were measured in the initial phase of the career of a unique group of highly skilled adolescent youth players from a soccer academy of high international repute, and career success was assessed 15 years later. Success was defined as actually playing for a premier league soccer team in a European competition for at least ten years in the 15-year period following data collection.

The technical staff of the soccer academy selected the soccer players with most potential and provided these individuals with the necessary resources for

Van Yperen is with the Dept. of Social and Organizational Psychology, University of Groningen, Groningen, The Netherlands. 
further development. Engagement in practice activities that have been specially designed to improve performance is called deliberate practice (Ericsson, Krampe, \& Tesch-Römer, 1993). Ericsson et al. (1993) postulated three types of constraints on deliberate practice. First, the motivational constraint refers to the commitment to one's goals that is required to engage in deliberate practice. Second, deliberate practice and successfully progressing into professional adult soccer require physical and mental effort (such as effective coping with stressful situations). Effortful activity can be sustained only for a limited time each day during extended periods without leading to exhaustion (i.e., the effort constraint). Third, the resource constraint refers to the resources that deliberate practice requires, such as access to coaches and training facilities, and social support. The purpose of the present research was to examine the importance of these three types of constraints for career success in professional adult soccer when statistically controlling for relevant variables. The control variables include number of siblings, ethnic origin, parental divorce (see method section for the rationale), and players' initial performance levels, that is, coaches' appraisals of players' performance levels at data collection. This latter variable represents possible initial differences in terms of, among other things, innate talent and time and effort already spent on soccer and additional activities. Controlling for innate talent seems contradictory to Ericsson's theoretical framework, but the possible effect of innate talent remains highly debated (e.g., Howe, Davidson, \& Sloboda, 1998).

\section{The Motivational Constraint}

The major finding emanating from goal-setting research is that a difficult goal, such as the goal to make it into professional adult soccer, leads to higher levels of performance than do easy or vague goals. To reach difficult goals, a high level of goal commitment is required, that is, the individual's determination to reach the goals (Locke \& Latham, 1990), which motivates the individual to engage in (further) deliberate practice. For example, Baker and Côté (2003) argued that commitment may be the most important attribute for the acquisition of expertise in sport because only individuals who are highly committed to their goals are willing to perform the thousands of hours of deliberate practice required to develop into an elite performer. Indeed, interviews with adolescent youth players and their coaches suggest that dedication, willingness to make sacrifices, and strong motives were associated with success in soccer (Holt \& Dunn, 2004). Using a retrospective cross-sectional design, Ward, Hodges, Starkes, and Williams (2007) showed that relative to subelite soccer players, elite players aged between 9 and 18 years of age reported higher levels of motivation to reach their goals. Accordingly, in the current study, it was expected that, relative to their counterparts who did not make it in this specific domain, the adolescent youth players who successfully progressed into professional adult soccer scored higher on goal commitment, that is, the degree to which they were determined in achieving their desired goals. 


\section{The Effort Constraint}

The pursuit of excellence may be a strenuous activity that draws on limited physical and mental resources. Successful individuals need the ability to recover to sustain a high level of deliberate practice for long periods of time without succumbing to exhaustion, that is, feelings of being drained or used-up (Schraw \& Ericsson, 2005). Exhaustion is associated with a lower ability to solve difficult, novel, or complex tasks, to overcome habitual responses, and to detect and correct errors, all of which negatively affect performance improvement (e.g., Boksem, Meijman, \& Lorist, 2006). The ultimately successful players may have had a better ability to recover from training activity, so that they were less vulnerable to exhaustion and its deleterious consequences for performance.

Although the effort constraint in the original deliberate practice theory (Ericsson et al., 1993) largely focused on physical effort, subsequent research demonstrated that effort also included mental effort (Starkes, Deakin, Allard, Hodges, \& Hayes, 1996). Exerting mental effort may be particularly important in stressful circumstances, either during deliberate practice or competition. Coping refers to the thoughts and behaviors people use to manage the internal and external demands of situations that are appraised as stressful (Lazarus \& Folkman, 1984). Two fundamentally different types of coping have been distinguished. Problem-focused coping is proactively doing something about the stressful situation; emotion-focused coping is defined as the cognitive regulation of stressful emotions. In general, it is appropriate to rely more on problem-focused coping in situations in which there is a potential for changing the outcome, whereas it is appropriate to rely more on emotion-focused coping in situation where there is little that can be done to change the outcome (Folkman \& Moskowitz, 2004). Prior research has indicated that individuals use both problem- and emotion-focused coping in almost all stressful episodes (Folkman \& Moskowitz, 2004; Taylor \& Stanton, 2007). For example, Nicholls, Holt, Polman, and Bloomfield (2006) demonstrated that professional rugby players used a variety of coping strategies to manage the stressors they experienced. Hence, it was predicted that relative to unsuccessful soccer players, successful soccer players may have been more likely to engage in coping behaviors in stressful circumstances they inevitably encountered during their soccer careers (and their lives in general).

\section{The Resource Constraint}

The resource constraint has typically been measured as a social constraint (Côté, Ericsson, \& Law, 2005), and includes resources such as access to coaches and school and homework support. In the current sample, these resources and other training facilities were provided by the soccer academy, and, accordingly, did not differentiate between the players. The focus in this research, therefore, was on one of the most important social resources in sport, that is, social support (Côté, 1999; Morgan \& Giacobbi, 2006; Van Yperen, 1998). Social support is defined as the perception or experience that one is loved and cared for by others, esteemed and valued, and part of a social network of mutual assistance and obligations (Taylor, 2007). Social support is typically associated with better sport perfor- 
mance (e.g., Rees, Hardy, \& Freeman, 2007; Ward et al., 2007). Hence, the tendency to seek social support, particularly when confronted with problems or drawbacks (Cohen \& Wills, 1985; Van Yperen, 1998), is likely to be associated with career success.

All together, it was hypothesized that relative to their counterparts who did not make it into professional adult soccer, the adolescent youth players who ultimately successfully progressed into professional adult soccer reported in the initial phase of their careers a higher level of goal commitment (Hypothesis 1), a lower level of exhaustion (Hypothesis 2a), higher engagement in coping behaviors (Hypothesis 2b), and a stronger tendency to seek social support (Hypothesis $3)$.

\section{Method}

\section{Sample and Descriptive Data}

In the soccer academy, there is only one team in each age group. At the end of each season, a selection takes place of players who can stay for at least one more year and those who have to leave and are replaced by new players who are sought out by scouts. The present sample consisted of all 65 male pupils from the age of $14(M=16.58, S D=1.40)$ representing four teams $(14-15$ year, $15-16$ year, 16-17 year, and > 17 year). The academy offered a highly structured and full program with emphasis on soccer training and school work, so that all participants may have spent more or less equal amounts of time training.

In line with the mission of the soccer academy, the primary goals of the youth players were: (1) Playing for a club in the Dutch premier league, (2) Playing for a team in a European premier league, and (3) Playing for a professional premier league club (see measures, "goal importance"). Hence, players were assumed to be successful if they met at least one of these goals. Specifically, participants were designated to the successful group if they had had (or still had) a contract with, and actually had played (or still played), for a premier league soccer team in a European competition for at least ten years in the 15-year period following data collection. A total of 18 participants met this criterion. Actually, each of these 18 players played hundreds of times for one or more premier league soccer clubs.

No differences between the successful and unsuccessful groups were observed with regard to age at the time of data collection $(M=16.58, S D=1.40, F(1,63)=$ $1.18, p=.28)$. At that time, most were still in high school $(95.4 \%)$, and three players $(4.6 \%)$ were in college. Differences between the groups were observed with regard to number of siblings, ethnic origin, and parental divorce. As shown in Table 1, relative to the unsuccessful group, successful participants had more siblings, were more often of non-White (or non-Dutch) ethnic origin (66.7\% vs. $\left.25.5 \%, \chi^{2}(1, N=65)=9.46, p=.002\right)$, and more often had divorced parents $\left(27.8 \%\right.$ vs. $\left.8.5 \%, \chi^{2}(1, N=65)=4.05, p=.04\right)$. Hence, number of siblings, ethnic origin, and parental divorce were statistically controlled for in subsequent analyses. 


\section{Table 1 Significant Differences Between the Successful and Unsuccessful Players}

\begin{tabular}{|c|c|c|c|c|c|c|}
\hline & $\begin{array}{l}M_{\text {succussful }} \\
\text { (SD) }\end{array}$ & $\begin{array}{l}M_{\text {unsuccussful }} \\
(S D)\end{array}$ & $F(\mathrm{df})$ & $p$ & $\begin{array}{l}\text { Partial } \\
\eta^{2}\end{array}$ & $\begin{array}{l}\text { I correlations } \\
\text { with } \\
\text { discriminant } \\
\text { function }{ }^{1}\end{array}$ \\
\hline Number of siblings & $2.22(1.56)$ & $1.34(1.24)$ & $F(1,63)=5.71$ & .02 & .08 & .50 \\
\hline Ethnic origin ${ }^{2}$ & $-.33(.97)$ & $.49(.88)$ & $\begin{array}{r}F(1,63)= \\
10.73\end{array}$ & .002 & .15 & -.47 \\
\hline Parental divorce ${ }^{3}$ & $-.44(.92)$ & $-.83(.56)$ & $F(1,63)=4.19$ & .04 & .06 & .45 \\
\hline $\begin{array}{l}\text { Initial performance } \\
\text { level }\end{array}$ & $.60(.89)^{4}$ & $-.26(.88)^{4}$ & $F(4,60)=9.38$ & .003 & .14 & .34 \\
\hline Goal commitment & $4.53(.41)^{5}$ & $4.17(.42)^{5}$ & $F(5,59)=9.47$ & .003 & .14 & .31 \\
\hline $\begin{array}{l}\text { Problem-focused } \\
\text { coping }\end{array}$ & $3.94(.80)^{5}$ & $3.70(.80)^{5}$ & $F(5,59)=4.34$ & .04 & .07 & .29 \\
\hline $\begin{array}{l}\text { Seeking social } \\
\text { support }\end{array}$ & $3.33(.78)^{5}$ & $2.87(.77)^{5}$ & $F(5,59)=4.57$ & .04 & .07 & .22 \\
\hline \multicolumn{7}{|c|}{$\begin{array}{l}{ }^{1} \text { Pooled within-groups correlations between discriminating variables and standardized canonical } \\
\text { function }\end{array}$} \\
\hline \multicolumn{7}{|c|}{${ }^{2}$ Non-White (i.e., non-Dutch) ethnic origin (-1) vs. Caucasian ethnic origin $(+1)$} \\
\hline \multicolumn{7}{|c|}{${ }^{3}$ Parents not divorced (-1) vs. Parents divorced (+1) } \\
\hline${ }^{4}$ Mean adjusted for num & nber of sibling & gs, ethnic origil & in and parental di & woret & & \\
\hline
\end{tabular}

\section{Measures}

Initial Performance Level. The coaches of the four teams were asked to assess the performance level of all the players on their team. The measure, which was developed by the technical staff of the soccer academy, consisted of 14 dimensions. Items tapped the participants' capacities in regard to technique, physical condition, and several specific soccer abilities (Van Yperen, 1995). The five response options ranged from 1 (insufficient) to 5 (very good). To standardize the mean and the variance of the appraisals of the various coaches, the raw scores were transformed into $z$ scores. The mean scale scores were then calculated. Coefficient alpha was .83 .

Goal Importance and Goal Commitment. To examine whether perceived goal importance may account for possible differences in goal commitment, the participants were first asked to indicate how important each goal was to them $(1=$ not important to me to $6=$ most important to me): (1) Playing for a club in the Dutch premier league, (2) Playing for a club in a European premier league, and (3) Playing for a professional premier league club. Cronbach's alpha was .77. Note that the participants were designated to the successful or the unsuccessful group based on whether they had secured contracts and played for professional premier league 
teams in a European competition for a minimum of ten years. Thus, successful participants had reached at least one of these (highly correlated) goals.

Next, goal commitment was measured using the reduced and improved version of the scale originally developed by Hollenbeck, O'Leary, Klein, and Wright (1989; Klein, Wesson, Hollenbeck, Wright, \& Deshon, 2001). Sample items are, "I am strongly committed to pursuing my goals," and "Quite frankly, I don't care if I achieve my goals or not" (reversed item). Response categories ranged from (1) totally disagree to (5) totally agree. Cronbach's alpha for the five-item scale was .78 .

Exhaustion was measured using a seven-item measure developed by Van Yperen (1997). The general stem was, "Did it occur last year?" Sample items are, "You felt tired more than usual," and "You were fed up with anything having to do with soccer". Five response categories were provided, ranging from (1) never to (5) always. Cronbach's alpha was .80.

Potential Stressors and Coping. To examine whether the perceived occurrence of stressors may account for possible differences in coping, the participants were first asked to indicate the extent to which a host of potential stressors had occurred in the previous year. The potential general stressors (25 items) represented different content areas, such as arguments with close others (relatives, friends), illnesses (self, others), school hassles, and financial problems. The soccer-specific stressors (25 items) included the pressure to perform, injuries, and arguments and problems with others (coaches, teammates, managers). Response categories ranged from (1) did not occur, or does not apply, to (5) occurred very often. Cronbach's alphas were .86 and .84 , respectively.

The participants then read the following:

The preceding parts dealt with problems and drawbacks every soccer player may encounter every now and then, such as arguments with others, problems at school or at work, an injury, or a poor performance. What do you do when you encounter such a problem or drawback?

Next, they responded to an abridged version of The Ways of Coping Questionnaire, a widely used self-report measure retaining a range of cognitive and behavioral strategies people use to manage stressors (e.g., Folkman \& Lazarus, 1985). Specifically, the participants were asked how they tend to cope with the above mentioned general and sport-specific stressors. They replied to the coping items that represented the two main categories of coping behavior (Lazarus \& Folkman, 1984): (1) problem-focused coping (e.g., "I'm making a plan of action and following it"; five items, Cronbach's alpha was .81); (2) emotion-focused coping (e.g., "I try to forget the whole thing by focusing on other things"; five items, Cronbach's alpha was .72). The response categories ranged from (1) never to (5) always.

Seeking Social Support. This measure, developed by Folkman and Lazarus (e.g., Folkman \& Lazarus, 1985), asks respondents to indicate their tendency to seek social support when encountering problems and drawbacks as listed above. Sample items are: "I seek the company of friends to have fun," and "Talk to some- 
one to find out more about the situation". Response options ranged from (1) never to (5) always. Cronbach's alpha was .77.

\section{Results}

It was first examined whether the participants who successfully progressed into professional adult soccer had higher initial levels of performance than their counterparts who did not reach the premier leagues in professional adult soccer. An ANCOVA controlling for number of siblings, ethnic origin, and parental divorce revealed that the ultimately successful participants were rated by their coaches as having a higher performance level relative to their unsuccessful counterparts (see Table 1). Hence, initial performance level was added as covariate in the subsequent analyses.

\section{Hypotheses Testing}

Hypothesis 1 was that the adolescent youth players who successfully progressed into professional adult soccer reported higher levels of goal commitment than their unsuccessful counterparts. First, however, it was examined whether the two groups differed on the perceived importance of the goal of making it into professional adult soccer. An ANCOVA controlling for number of siblings, ethnic origin, parental divorce, and initial performance level yielded no differences, $F(5,59)=$ $1.08, p=.30\left(M_{\text {total }}=4.57, S D=1.04\right)$. Next, the same analysis was executed again with goal commitment as the dependent variable. Empirical support was obtained for Hypothesis 1: relative to the unsuccessful participants, the ultimately successful participants reported higher goal commitment at the time they were enrolled at the school (see Table 1). The effect size (partial $\eta^{2}$ ) of .14 indicates that this effect should be interpreted as large (Cohen, 1988, pp. 283-288).

To exclude the possibility that different numbers of practice hours may account for possible differences in exhaustion, analyses were conducted to test whether, relative to their unsuccessful counterparts, the successful participants differed in the self-reported, average number of hours per week spent on soccer during the season. As expected, owing to their uniform program, the ANCOVA revealed no differences between the groups in this regard $\left(M_{\text {total }}=11.94\right.$ per week, $S D=4.40, F(5,59)=.23, p=.63)$. Furthermore, the participants were asked whether they undertook training at their own initiative (alone or with others) on a regular basis during the season, and whether they trained at their own initiative (alone or with others) during the off-season $(1=$ totally disagree to $5=$ totally agree $)$. No differences were found between the groups $\left(M_{\text {total }}=3.37, S D=.82\right.$, $F(5,59)=.41, p=.53$, and $M_{\text {total }}=3.75, S D=.95, F(5,59)=2.06, p=.16$, respectively). This may suggest that no differences in number of practice hours existed.

Unexpectedly, however, no empirical support was found for Hypothesis $2 a$. The ANCOVA controlling for number of siblings, ethnic origin, parental divorce, and initial performance level yielded no differences between the groups in exhaustion, $F(5,59)=.08, p=.76\left(M_{\text {total }}=1.87, S D=.53\right)$.

Before Hypothesis $2 b$ was tested, possible differences in the perceived occurrence of stressors were examined. The ANCOVA yielded no differences with regard to soccer-specific stressors, $F(5,59)=1.39, p=.24\left(M_{\text {total }}=1.66, S D=.37\right)$ 
and general stressors, $F(5,59)=2.14, p=.15\left(M_{\text {total }}=1.65, S D=.37\right)$. In contrast, relative to the unsuccessful participants, the successful participants were more likely to use problem-focused coping strategies (see Table 1), but no differences were found with regard to emotion-focused coping, $F(5,59)=.71, p=.40\left(M_{\text {total }}\right.$ $=2.73, S D=.83$ ), which partially supports Hypothesis $2 b$. The effect size (partial $\eta^{2}$ ) of .07 (see Table 1) indicates that the link between problem-focused coping and career success should be interpreted as moderate to large, and, accordingly, meaningfully different (Cohen, 1988, pp. 283-288).

As shown in Table 1, an ANCOVA controlling for number of siblings, ethnic origin, parental divorce, and initial performance level provided empirical support for Hypothesis 3: the successful participants were more likely to seek social support than their unsuccessful counterparts.

Finally, and most importantly, a discriminant analysis was conducted to examine how many individuals could be classified correctly on the basis of their scores on the significant predictor and control variables. In this analysis, the set of significant predictors (see Table 1) was used to generate the linear discriminant function that best distinguished between the successful group and unsuccessful group. This function was highly significant, $\chi^{2}(7, N=65)=34.27, p<.001$. Most interestingly, $84.6 \%$ of the participants (55 out of 65$)$ were correctly classified as ultimately successful or unsuccessful (see Table 2).

To address the question how many participants could be classified on the basis of the significant psychological factors alone (i.e., goal commitment, problem-focused coping, and seeking social support; see Table 1), a second discriminant analysis was conducted. Again, the linear discriminant function was significant, $\chi^{2}(3, N=65)=11.55, p<.01$. Also on the basis of the significant psychological factors alone, a great majority $(72.3 \%)$ of the participants (47 out of 65 ) were correctly classified as ultimately successful or unsuccessful (see Table 3).

\section{Discussion}

In this prospective study on career success in professional adult soccer, an impressive $84.6 \%$ of the adolescent youth players were correctly classified as successful or unsuccessful on the basis of their scores on the significant predictor and control variables. When statistically controlling for initial performance level (which

\section{Table 2 Absolute Numbers and Percentages of Correctly Classified Cases on the Basis of Scores on the Significant Predictor and Control Variables (See Table 1)}

\begin{tabular}{clccc}
\hline & & \multicolumn{2}{c}{$\begin{array}{c}\text { Predicted Group } \\
\text { Membership }\end{array}$} & Total \\
\cline { 3 - 3 } & & Successful & Unsuccessful & \\
\hline Original Count & Successful & 15 & 3 & 18 \\
& Unsuccessful & 7 & 40 & 47 \\
Percentage & Successful & 83.3 & 16.7 & 100 \\
& Unsuccessful & 14.9 & 85.1 & 100 \\
\hline
\end{tabular}


Table 3 Absolute Numbers and Percentages of Correctly Classified Cases on the Basis of Scores on the Significant Psychological Factors Alone (i.e. Goal Commitment, Problem-Focused Coping, and Social Support; See Table 1)

\begin{tabular}{llccc}
\hline & & \multicolumn{2}{c}{$\begin{array}{c}\text { Predicted Group } \\
\text { Membership }\end{array}$} & Total \\
\cline { 3 - 4 } & & Successful & Unsuccessful & \\
\hline Original count & Successful & 12 & 6 & 18 \\
& Unsuccessful & 12 & 35 & 47 \\
Percentage & Successful & 66.7 & 33.3 & 100 \\
& Unsuccessful & 25.5 & 74.5 & 100 \\
\hline
\end{tabular}

reflects, among other things, possible differences in innate talent and time and effort already spent on soccer and related activities) and other control variables, the findings suggest that psychological factors are important for predicting career success in soccer. On the basis of the three significant psychological factors alone (i.e., goal commitment, problem-focused coping, and seeking social support), still a great majority (72.3\%) of the participants were correctly classified as ultimately successful or unsuccessful.

Ericsson et al. (1993) argued that the pursuit of excellence involves operating within three types of constraints on deliberate practice. With regard to the motivational constraint, the results demonstrate that the goal of making it into professional adult soccer was high and largely invariant in the current sample. However, relative to their unsuccessful counterparts, those who successfully progressed into professional adult soccer felt more psychologically bound to their goals, so that their willingness to put effort into goal attainment, their persistence in pursuing their goals over time, and their reluctance to lower or abandon their goals may have been stronger.

With regard to the effort constraint, no differences in exhaustion were observed between the successful and unsuccessful participants, suggesting that there were no differences between the groups with regard to their abilities to recover from the high physical and mental demands that are inherently associated with pursuing a career in professional soccer. In this regard, it is noteworthy that the soccer academy offered a highly structured and full program with emphasis on soccer training and school work, so that all participants may have spent more or less equal amounts of time training. This highly structured environment, exposing the adolescent youth players to a limited number of practice hours as well as to appropriate medical monitoring, may account for the low overall levels of exhaustion in this sample.

As expected, relative to the unsuccessful participants, the successful participants reported higher engagement in problem-focused coping behavior. And with regard to the resource constraint, they were also more likely to seek social support when encountering problems and drawbacks. This suggests that relative to the unsuccessful participants, the successful participants may have been better able to adapt to the stressful circumstances they inevitably encountered during their 
soccer careers, possibly by using their coping skills and social resources more frequently and more flexibly.

Although a high percentage $(84.6 \%)$ of participants were correctly classified as successful or unsuccessful, some limitations warrant mention. First, 15 years is a huge time gap, and no process variables were collected in between, so that one can only speculate about how the significant predictor variables may have affected career success. Second, the three psychological constraints on deliberate practice (Ericsson et al., 1993) were the central focus of this research, and these variables alone could correctly classify $72.3 \%$ of the participants as ultimately successful or unsuccessful. However, differences between the successful and unsuccessful participants were also observed with regard to initial performance and demographic variables. That is, at data collection, the participants who successfully progressed into professional adult soccer were rated by their coaches as having a higher performance level relative to their unsuccessful counterparts. Particularly in competitive contexts, high value is placed on achievement, success, and excellence so that the individuals who were perceived as high potentials may have received most attention and support which may have facilitated further development (e.g., Solomon, Striegel, Eliot, Heon, \& Maas, 1996).

More remarkable is the finding that, relative to the unsuccessful group, successful participants had more siblings, were more often of non-White (or nonDutch) ethnic origin, and more often had divorced parents. In speculating about these remarkable results, siblings may form a kin group bound by strong ties of trust and support, and may increase social skills which may be helpful to progress in team sports in particular. And being a member of an ethnic minority and having divorced parents may help to develop coping skills and attitudes that are helpful in dealing with all kind of problems or drawbacks. For example, in a Newsweek interview (Meacham, 2008), Barack Obama, whose parents divorced when he was 2 years old, revealed that

my strength actually comes, in my case, from the absence of a father. At some level I had to raise myself. . . . if I think about how I have been able to navigate some pretty tricky situations in my life, it has to do with the fact that I had to learn to trust my own judgment; I had to learn to fight for what I wanted. I actually think that maybe having an absent father meant also that . . . you have to grow up faster ... that maybe carries over into how you approach the world generally, that you need to take responsibility and make sure that you're able to solve problems and step into the breach because there's nobody other than you who's going to solve them.

For the current study, however, it is most important that the focal predictor variables were associated with career success in soccer when statistically controlling for these demographic variables. But the observed pattern also underlines that becoming successful in one's sport is a complex and delicate process influenced by a variety of additional psychological, physical, social, and organizational factors (e.g., Baker, 2003; Gould, Dieffenbach, \& Moffett, 2002; Reilly, Williams, Nevill, \& Franks, 2000).

In closing, the most important contribution of this prospective study is that it shows that psychological factors such as goal commitment, engagement in coping 
behaviors, and seeking social support differentiate, when statistically controlling for initial performance and demographic characteristics, between adolescent youth soccer players who finally successfully progressed into professional adult soccer and those who did not. Suggestive evidence exists that both goal commitment (Raabe, Frese, \& Beehr, 2007) and the tendency to engage in coping behaviors and social support seeking (Taylor \& Stanton, 2007) can change with psychosocial intervention, probably as a function of deliberate practice.

\section{Acknowledgments}

The author thanks Piet Bon, Louis van Gaal, and Co Adriaanse who made this research possible.

\section{References}

Abbott, A., \& Collins, D. (2002). A theoretical and empirical analysis of a 'state of the art' talent identification model. High Ability Studies, 13, 157-178.

Baker, J. (2003). Early specialization in youth sport: a requirement for adult expertise? High Ability Studies, 14, 85-94.

Baker, J., \& Côté, J. (2003). Resources and commitment as critical factors in the development of 'gifted' athletes. High Ability Studies, 14, 139-140.

Baker, J., \& Horton, S. (2004). A review of primary and secondary influences on sport expertise. High Ability Studies, 15, 211-228.

Bloom, B.S. (1985). Developing talent in young people. New York: Ballantine Books.

Boksem, M.A.S., Meijman, T.F., \& Lorist, M.M. (2006). Mental fatigue, motivation and action monitoring. Biological Psychology, 72, 123-132.

Cohen, J. (1988). Statistical power analysis for the behavioral sciences (2nd ed.). Hillsdale, NJ: Lawrence Erlbaum.

Cohen, S., \& Wills, T.A. (1985). Stress, social support, and the buffering hypothesis. Psychological Bulletin, 98, 310-357.

Côté, J., Baker, J., \& Abernethy, B. (2003). From play to practice: A developmental framework for the acquisition of expertise in team sport. In J. Starkes \& K.A. Ericsson (Eds.), Recent advances in research on sport expertise (pp. 89-114). Champaign, IL: Human Kinetics.

Côté, J. (1999). The influence of the family in the development of talent in sport. The Sport Psychologist, 13, 395-417.

Côté, J., Ericsson, K.A., \& Law, M.P. (2005). Tracing the development of athletes using retrospective interview methods: A proposed interview and validation procedure for reported information. Journal of Applied Sport Psychology, 17, 1-19.

Durand-Bush, N., \& Salmela, J.H. (2002). The development and maintenance of expert athletic performance: Perceptions of world and Olympic champions. Journal of Applied Sport Psychology, 14, 154-171.

Ericsson, K.A., Krampe, R.T., \& Tesch-Römer, C. (1993). The role of deliberate practice in the acquisition of expert performance. Psychological Review, 100, 363-406.

Folkman, S., \& Moskowitz, J.T. (2004). Coping: Pitfalls and promise. Annual Review of Psychology, 55, 745-774.

Folkman, S., \& Lazarus, R.S. (1985). If it changes it must be a process: Study of emotion and coping during three stages of a college examination. Journal of Personality and Social Psychology, 48, 150-170.

Gould, D., Dieffenbach, K., \& Moffett, A. (2002). Psychological characteristics and their development in Olympic champions. Journal of Applied Sport Psychology, 14, 172-204. 
Hollenbeck, J.R., O’Leary, A.M., Klein, H.J., \& Wright, P.M. (1989). Investigation of the construct-validity of a self-report measure of goal commitment. The Journal of Applied Psychology, 74, 951-956.

Holt, N.L., \& Dunn, J.G.H. (2004). Toward a grounded theory of the psychosocial competencies and environmental conditions associated with soccer success. Journal of Applied Sport Psychology, 16, 199-219.

Klein, H.J., Wesson, M.J., Hollenbeck, J.R., Wright, P.M., \& Deshon, R.P. (2001). The assessment of goal commitment: A measurement model meta-analysis. Organizational Behavior and Human Decision Processes, 85, 32-55.

Lazarus, R.S., \& Folkman, S. (1984). Stress, appraisal and coping. New York: Springer.

Locke, E.A., \& Latham, G.P. (1990). A theory of goal setting \& task performance. (xviii ed.) Upper Saddle River, NJ, US: Prentice-Hall, Inc.

Meacham, J. (2008). I had to learn to fight. Newsweek, September 1 (see also www.newsweek.com/id/155175).

Morgan, T.K., \& Giacobbi, P.R. (2006). Toward two grounded theories of the talent development and social support process of highly successful collegiate athletes. The Sport Psychologist, 20, 295-313.

Nicholls, A.R., Holt, N.L., Polman, R.C.J., \& Bloomfield, J. (2006). Stressors, coping, and coping effectiveness among professional rugby union players. The Sport Psychologist, 20, 314-329.

Raabe, B., Frese, M., \& Beehr, T.A. (2007). Action regulation theory and career self-management. Journal of Vocational Behavior, 70, 297-311.

Rees, T., Hardy, L., \& Freeman, P. (2007). Stressors, social support, and effects upon performance in golf. Journal of Sports Sciences, 25, 33-42.

Reilly, T., Williams, A.M., Nevill, A., \& Franks, A. (2000). A multidisciplinary approach to talent identification in soccer. Journal of Sports Sciences, 18, 695-702.

Schraw, G., \& Ericsson, K.A. (2005). An interview with K. Anders Ericsson. Educational Psychology Review, 17, 389-412.

Solomon, G.B., Striegel, D.A., Eliot, J.F., Heon, S.N., \& Maas, J.L. (1996). The self-fulfilling prophecy in college basketball: Implications for effective coaching. Journal of Applied Sport Psychology, 8, 44-59.

Starkes, J.L., Deakin, J.M., Allard, F., Hodges, N.J., \& Hayes, A. (1996). Deliberate practice: What is it anyway? In K.A. Ericsson (Ed.), The road to excellence: The acquisition of expert performance in the arts and sciences, sports and games (pp. 81-106). New Jersey: Lawrence Erlbaum.

Szymanski, S., \& Zimbalist, A.S. (2005). National pastime: How Americans play baseball and the rest of the world plays soccer. Washington, DC: Brookings Institution Press.

Taylor, S.E. (2007). Social support. In H.S. Friedman \& R.C. Silver (Eds.), Foundations of Health Psychology (pp. 145-171). New York: Oxford University Press.

Taylor, S.E., \& Stanton, A.L. (2007). Coping resources, coping processes, and mental health. Annual Review of Clinical Psychology, 3, 377-401.

Vaeyens, R., Lenoir, M., Williams, A.M., \& Philippaerts, R.M. (2008). Talent identification and development programmes in sport - Current models and future directions. Sports Medicine (Auckland, N.Z.), 38, 703-714.

Van Yperen, N.W. (1992). Self-enhancement among major league soccer players: The role of importance and ambiguity on social comparison behavior. Journal of Applied Social Psychology, 22, 1186-1198.

Van Yperen, N.W. (1995). Interpersonal stress, performance level, and parental support: A longitudinal study among highly skilled young soccer players. The Sport Psychologist, 9, 225-241.

Van Yperen, N.W. (1997). Inequity and vulnerability to dropout symptoms: An exploratory causal analysis among highly skilled youth soccer players. The Sport Psychologist, $11,318-325$. 
Van Yperen, N.W. (1998). Being a SportParent: Buffering the effect of your talented child's poor performance on his or her subjective well-being. International Journal of Sport Psychology, 29, 45-56.

Ward, P., Hodges, N.J., Starkes, J.L., \& Williams, M.A. (2007). The road to excellence: deliberate practice and the development of expertise. High Ability Studies, 18, 119153. 